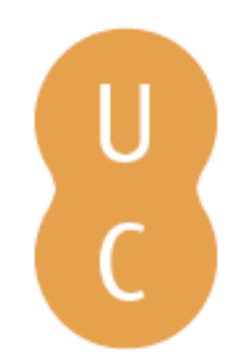

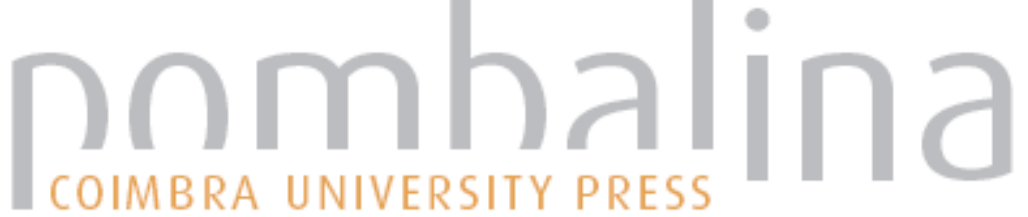

\section{A memória do espaço no espaço da memória: entre a analística e os primórdios da cronística medieval}

\author{
Autor(es): $\quad$ Gama, Orlando \\ Publicado por: Associação Portuguesa de Estudos Clássicos; Centro de Estudos \\ URL \\ DOI: $\quad$ DOI:http://dx.doi.org/10.14195/978-989-8281-69-2_16 \\ Accessed : $\quad$ 26-Apr-2023 02:18:00
}

A navegação consulta e descarregamento dos títulos inseridos nas Bibliotecas Digitais UC Digitalis, UC Pombalina e UC Impactum, pressupõem a aceitação plena e sem reservas dos Termos e Condições de Uso destas Bibliotecas Digitais, disponíveis em https://digitalis.uc.pt/pt-pt/termos.

Conforme exposto nos referidos Termos e Condições de Uso, o descarregamento de títulos de acesso restrito requer uma licença válida de autorização devendo o utilizador aceder ao(s) documento(s) a partir de um endereço de IP da instituição detentora da supramencionada licença.

Ao utilizador é apenas permitido o descarregamento para uso pessoal, pelo que o emprego do(s) título(s) descarregado(s) para outro fim, designadamente comercial, carece de autorização do respetivo autor ou editor da obra.

Na medida em que todas as obras da UC Digitalis se encontram protegidas pelo Código do Direito de Autor e Direitos Conexos e demais legislação aplicável, toda a cópia, parcial ou total, deste documento, nos casos em que é legalmente admitida, deverá conter ou fazer-se acompanhar por este aviso.

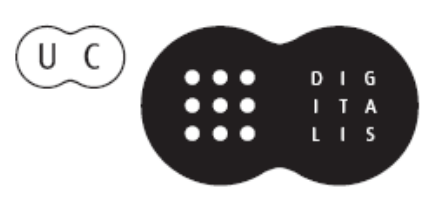




\section{Espaços e Paisagens}

Antiguidade Clássica

e Heranças Contemporâneas

Vol. III

Francisco Oliveira, Jorge Oliveira e Manuel Patrício

IMPRENSA DA UNIVERSIDADE DE COIMBRA 


\title{
A MEMÓRIA DO ESPACO NO ESPAÇO DA MEMÓRIA: ENTRE A ANALISSTICA E OS PRIMÓRDIOS DA CRONÍSTICA MEDIEVAL ${ }^{1}$
}

\author{
ORLANDO GAMA \\ Instituto Politécnico de Bragança
}

\begin{abstract}
The Memory of Space in the Space of Memory: notes on Lusitania in Medieval Historiographic Narrative.

The relationship between Past and Memory isn't pacific. Reflection upon these matters requires a special attention with identity forms and narrative speech. There's no identity without memory. How possible is to study the identity in medieval times? how to read medieval iconography and thought in Iberia and Portugal's formation? We have to look forward and perceive the historicity of the identity's idea and the coexistence of different levels of identity. So, it's very important to analyse the data of narrative speech (particularly the Chronicle's) about that subjects, in connection with the evolution of the space representation and the meaning of Lusitania's idea.
\end{abstract}

Keywords: historiography, Lusitania, memory, power, space.

Palavras-chave: espaço, historiografia, Lusitânia, memória, poder.

A relação do passado com a memória não é, de todo, pacífica. Nem sequer existe uma condição de linearidade e de espontaneidade entre o vivido e o registado, na forma como cada comunidade, em qualquer época, se concebe e se identifica. Para o período que se convencionou designar de medieval, a dificuldade de análise é, naturalmente, acrescida pela distância temporal e mental que nos separam e pelas limitações de quantidade e qualidade da sua documentação.

Como se sabe, a Lusitânia começa por se definir, historicamente, como designação regional (determinando a sua futura e primordial forma na memória nacional) com a organização administrativa romana e, posteriormente, numa solução de continuidade, com a ocupação sueva e visigótica. Não cabe aqui a exploração e explicitação da complexa e abundante discussão em torno dos factores que enformam as origens da nacionalidade, nomeadamente o da permanência/alteração de estruturas político-administrativas e da sua evolução, no quadro relacional da geografia física e humana e das características sócioculturais do ocidente peninsular.

Um outro factor, estritamente ligado ao anterior, remete para as condições de manutenção do nome Lusitânia, em íntima relação com a evolução e

\footnotetext{
${ }^{1}$ Algumas notas deste texto foram editadas em Rumos e Escrita da História. Estudos em Homenagem a A. A. Marques de Almeida, ed. M. Fátima Reis. Lisboa, Edições Colibri, 2006, pp.661-679. Por sua vez, o que aqui se apresenta, por imposição das regras de publicação do presente volume, corresponde à totalidade da comunicação apresentada.
} 
limites das posteriores configurações político-administrativas vigentes no território peninsular medievo, em resultado da sua longa e atribulada trama conjuntural. Sabemos que o nome dos lugares não se desliga das condições históricas e populacionais que os caracterizam. A solução de continuidade atrás mencionada é, no entanto, quebrada, a partir do início do século VIII, pela presença árabe, que, numa leitura de época, constitui uma espécie de pausa no "natural" evoluir da história peninsular. Aliás, pura recriação discursiva. Não só porque a influência árabe foi um facto de indiscutível peso (pela duração, expressão territorial e qualidade das influências), mas também porque a Reconquista, baseada na afirmação do conceito de legitimidade jurisdicional (político-religiosa) sobre o espaço era, na verdade, remetido para o direito ao exercício da autoridade sobre a gestão desse mesmo espaço, não implicando, necessariamente, luta e expulsão, havendo muitos exemplos de coabitação ${ }^{2}$. As centúrias seguintes serão, efectivamente, ocupadas entre essa mesma Reconquista e a (re)configuração de um novo mapa político da Península, com o que isso implicou na formação de novos e afirmativos poderes e na introdução de novas visões e concepções do espaço. A Lusitânia sofre o seu primeiro grande embate. Numa realidade em aberto, em longa, disputada e difícil construção, já não havia lugar para a sua manutenção como realidade político-administrativa. Mas não foi completamente esquecida, embora não fosse do interesse, nem constituísse preocupação imediata dos reinos em formação. Renasce, então, com a identidade que lhe ficará até hoje: no seio da estruturação do discurso historiográfico, vindo mesmo a assumir, mais tarde, contornos de figura alegórica. Mas a sua ligação à realidade não foi descomprometida. A sua invocação narrativa, mesmo que residual, ou mesmo a sua ausência, em tessituras discursivas diferenciadas, só pode constituir-se em significativo sinal de valor. Na verdade, tal como adiante demonstraremos, as variantes na invocação de referentes, em contextos diversificados, projectada numa semântica historiográfica plural, são um claro sinal da forma de entender e construir a realidade, enfim, demonstrando-se, em última análise, a importância dos textos na percepção do campo mental e do aparelho ideológico dos seus produtores.

As fontes utilizadas neste breve apontamento são, na essência da sua forma e conteúdo, recorrendo à divisão notada por Pierre David ${ }^{3}$, de dois tipos: as analísticas e as cronísticas. Se bem que privilegiando as segundas. Demarcação que, para o que nos move, não é de secundarizar. Na verdade, ela revela numa primeira abordagem, uma identidade cronológica pois, como salientou o referido autor, os registos historiográficos primordiais da cultura europeia assumiram esta forma, remontando os exemplares iniciais ao século VIII, correspondendo à fixação de notas anuais inscritas nas "tábuas pascais" e transmitindo-se, em forma de estrutura e conteúdos, até às crónicas régias dos séculos XIII a XV. Num segundo patamar saliente-se que existe

${ }^{2}$ Situação semelhante à que se viveu durante a autoridade muçulmana. $C f$. J. Antonio Maravall 1964 268-269.

${ }^{3}$ Pierre David 1947. 
uma conformidade de contexto de produção e de uso eminentemente prático, que remete para o meio monástico, preocupado em compilar dados de cariz político, militar e eclesiástico, fixando a memória do que se considerava digno de registo. Note-se, no entanto, que neste grupo de fontes, a par das analísticas, encontramos já formas mais elaboradas na composição e no conteúdo, embora incipientes, comparando com os registos cronísticos posteriores (século XIII em diante). Conjunto de registos que abrem, de forma sistemática, a historiografia do ocidente peninsular, produzida a partir da reconquista. Trabalho de análise que deverá, como sempre nestes casos, ser tido por provisório, dadas as dificuldades que ainda persistem no quadro de uma necessária e urgente contextualização, delimitação cronológica e estabelecimento da tradição textual de cada um dos registos citados, e entre eles.

Numa leitura das referidas fontes, observamos que a noção de Lusitânia é utilizada com pouca frequência, sendo mencionada em cinco destes textos: na Chronica Gothorum (versão extensa e versão abreviada), na Translatio et Miracula S. Vicentii, na Vita Sancti Theotoni, nos Annales D. Alfonsi e no De Expugnatione Olisiponis A.D. MCXLVII, concretamente na Crucesignati Anglici Epistola de Expugnatione Oilisiponis. Antes de mais, verifica-se, pois, uma subdivisão entre as referências e os silêncios, ou melhor, as ausências. Neste último caso, algumas notas poderão ajudar a entender melhor esta constante. Encontramos aí fontes analísticas e narrativas que se apresentam com várias procedências, cronologia e contextos de produção. No entanto, alguns factores comuns ajudam-nos a agrupá-los e a dar algum sentido ao seu perfil e código discursivos, apesar de conscientes dos perigos que a generalização acarreta ${ }^{4}$. Mas como proceder quando, à referida genética do discurso historiográfico, se junta uma linha condutora que entra na própria estrutura do discurso narrativo posterior e mais elaborado?

Façamos uma breve abordagem no campo das fontes cronísticas. A análise, assumidamente encarada como parcial e não exaustiva, recai sobre o primeiro registo ibérico comummente considerado nesta categoria: a Primera Crónica General de España. Que mandó componer Alfonso el Sabio y se continuaba Bajo Sancho IV en $1289^{5}$. Duas razões sustentam a nossa escolha: por um lado, por ser precursora na afirmação e estruturação de um discurso cronístico régio; por outro, por ter uma identidade espacial e política (castelhana) mais vincada no contexto peninsular. Importa realçar, para o efeito, algumas notas extraídas do estudo que acompanha a publicação desta fonte:

1 - O texto da crónica não possui homogeneidade, nem na forma, nem no conteúdo. $\mathrm{O}$ reinado de Afonso $\mathrm{X}$ é marcado por vários períodos de actividade científico-literária ${ }^{6}$, com intervenção de tradutores, "ayuntadores"

\footnotetext{
${ }^{4}$ Para uma análise do tema veja-se o nosso artigo, op.cit.

${ }^{5}$ Utilizamos a edição da responsabilidade de R. Menéndez Pidal 1955. A menção a esta fonte far-se-á pela sigla $C G E$.

${ }^{6}$ Menéndez Pidal fala-nos de 2 períodos: 1250-1260 e 1269-1284, fim do reinado.
} 
ou compiladores e capituladores. Acresce o trabalho de intervenção directa do próprio Afonso X.

2 - A crónica foi concluída sob os auspícios de Sancho IV, filho de Afonso $\mathrm{X}$, tendo-se iniciado, pelo menos, em 1270 e estando ainda a ser redigida em 1289 .

3 - Constata-se uma bipartição, em dois tomos, que mais do que física, corresponde a algo constitutivo da própria Crónica, sendo cada tomo referente a cada reinado dos monarcas mencionados. Afonso $\mathrm{X}$ revela, nas suas fontes e nos conteúdos perpetuados, um significativo gosto erudito pelo passado legitimador.

4 - A divisão interna da obra é feita por partes de desigual tamanho, cada uma referente a cada senhorio que dominou España, com uma significativa falta de atenção ao domínio árabe e uma identificação, na linha dos anais e fontes anteriores, entre a história peninsular e história dos godos.

5 - Os 108 primeiros capítulos, crê-se de vários autores/compiladores, revelam uma falta de unidade e um estilo arcaizante, provavelmente de geração mais velha e com possível intervenção directa e activa de Afonso $\mathrm{X}$; na mesma linha, Menéndez Pidal aponta uma continuidade até ao final da história gótica (cap. 565), revelando uma certa unidade material com o grupo anterior; ainda de salientar que, até ao capítulo 965 (morte de Afonso VI), o texto apresenta uma característica própria: a forma de redacção aproximada às fontes anteriores - os anais - sendo, enfim, os últimos 170 capítulos significativamente diferentes, num relato mais contemporâneo, em forma e conteúdo da própria redacção.

Neste sentido, façamos uma rápida leitura dos conteúdos e do enquadramento do tema da Lusitânia neste texto. Começaremos por notar que, de acordo com o que atrás afirmámos, verifica-se uma alternância entre modos de fixação do nome ("Lusitania", "Luzenna", "Luzeña", "Lucenna"), não só, certamente, devido às múltiplas fontes e compiladores/tradutores, como também às múltiplas influências linguísticas que produziram o vernáculo, com forte influência da oralidade na grafia, particularmente em termos cujo uso quotidiano era diminuto. Comprova-se esta asserção pelo facto da aplicação do termo de origem latina (Lusitania/Lusitanna) apenas surgir nos capítulos 7 (p.10, a propósito da presença e acção povoadora de Hércules) e 77 (p. 56, sobre Sertório e Pompeu), entre a corrente utilização vernácula.

Mas afinal em que contextos surge o tema? A este propósito poderemos estabelecer algumas categorias de uso, respeitando a referida multiforme 
divisão interna da obra que destacámos nas notas iniciais anteriores. Senão vejamos:

Para os 108 primeiros capítulos,

a) a da origem e identificação do topónimo, marca da tradição clássica que permanecerá em transdiscursividade posterior, nomeadamente em textos historiográficos dos séculos seguintes - ex. cap. 3 (p.6) e 7 (p.10). Através desta referência acentua-se uma clara separação entre Portugal e a Lusitânia, com diversos antecedentes histórico-mitológicos: aquele, curiosamente, radicando a origem na Galiza; esta, demarcando uma região entre o Guadiana e o Tejo, terra dos Lusios, invocando a presença de Hércules.

b) em estreita ligação com o ponto anterior, a da afirmação da matriz espacial de origem étnica, contribuindo para a sua leitura como etnónimo cap.s 3 (p. 6, "Lusios"), 42 (p. 28, "los de Luzenna").

c) a da identidade vincada pela autonomia de "los de tierra de Luzenna" (cap. 39, p. 27), que merece o propósito do relato do episódio de Viriato ("y era natural de tierra de Luzenna", cap. 43, p. 28), aliás,

remetendo para a categoria de localização de acontecimentos históricos relevantes (passim).

Até ao capítulo 565:

procede-se à continuação do relato sobre a presença romana na península, permitindo o uso regular do tema para contextualização de acontecimentos e definição da matriz espacial da identidade peninsular. Não sem hesitações e incongruências, pois,

se mantém firme a divisão entre Galiza e Luzenna (cap. 367, p. 210; 372, p. $212 ; 374$, p. $213 ; 417$, p. 238), tal como surgira inicialmente,

ainda reforçando essa cartografia através da separação com Coimbra (cap. 423 , p. 241), fazendo recuar o limite para sul,

recupera da primeira parte (cap. 41, p. 27) a categoria de circunscrição administrativa, através da noção de "província" e admite a sua coincidência com o Algarve (cap. 366, p. 209), para mais à frente redimensionar o espaço e juntar a referência ao Guadiana e a Mérida (cap. 374, p. 213) e terminar numa significativa "provincia de Luzenna, que es tierra de Badajoz et dell Algarve" (cap. 417, p. 239).

A partir do capítulo 565:

a) o fim da história gótica e o ciclo dos reis asturianos fica, desde logo, marcado por uma significativa menção do reinado de Afonso III, levando-nos a estabelecer uma ponte com as fontes analísticas já analisadas: os $A P V$ e a sua apresentação na $C G$. Fonte de origem regional propusera, como acima vimos, uma menção enquadrada por referências espaciais coerentes com o território que viria a ser português, remetendo para a escala de leitura intermédia assumida pela Lusitânia. Na CGE, cap. 658, pp. 377-378, o mesmo assunto e cronologia, tratados significativamente de modo diferente, abreviado e omisso no que toca à Lusitânia: "[Afonso III] Et poblo en Portogal estas cibdades que 
eran destroydas de moros: Bragana, Viseo, Lamego, Edanna et el Puerto. (...) Et poblo y otrossi toda essa tierra bien fastal rio de Taio";

b) mais do nunca surgem as incongruências com o texto anterior. Atentese no cap. 673, p. 385, em que separa Mérida da "tierra de Luzenna"; no cap. 722 , p. 423, em que separa a Galiza de Luzenna pelo rio Douro (quando atrás dissera ser Luzenna o Algarve...); para, logo a seguir, distinguir a Galiza de Portugal (cap. 744, p. 443); mas, afinal, ainda consegue demarcar Portugal de Luzenna, sendo esta "tierra de Badaioz et de Mérida" (!), (cap. 805, p. 486); para, no fim, coerentemente com as conclusões que acima retirámos das fontes anteriores, aproximar, pela via da presença árabe, Portugal e a Lusitânia (cap. 815 , p. 495). Como vimos, fora esta identidade de destino que legitimara, na leitura das fontes anteriores, o papel e a acção dos monarcas portugueses (particularmente D. Afonso Henriques), bem como a matriz espacial do regnum.

c) por último, importa referir que, no conjunto dos capítulos finais (a partir do cap. 965), apenas surge uma breve menção a "Luzenna", identificada com as ribeiras do Guadiana (cap. 968, p. 649), situação coerente com um discurso de outra natureza, mais próximo cronologicamente e consentâneo com um enquadramento espacial definido pela matriz político-administrativa contemporânea da escrita.

Se bem que provisória, por questões de economia de tempo e de discurso, esta análise permite-nos perceber os efeitos da transdiscursividade e a importância de se equacionar o uso situado da linguagem, bem como a representatividade contextual do tema na evolução do discurso historiográfico. Remete-nos, ainda, para as condições de produção e recepção do textos, invocando estratégias discursivas no seio das várias tessituras de poderes e apela para a necessidade de proceder a estudos mais sistemáticos sobre a linguagem, o espaço e o poder, privilegiando perspectivas comparativas e filiações significativas.

\section{Bibliografia}

Pierre David (1947), Études Historiques sur la Galice et le Portugal du VI au XII siècle. Lisboa.

J. Antonio Maravall (1964), El Concepto de España en la Edad Media. Madrid, Instituto de Estudios Politicos, 268-269.

R. Menéndez Pidal (1955), Primera Crónica General de España. Que mandó componer Alfonso el Sabio y se continuaba Bajo Sancho IV en 1289. Madrid, Ed. Gredos. 